\title{
Chemical Composition of Four Cultivated Tropical Bamboo in Genus Gigantochloa
}

\author{
Razak Wahab ${ }^{1}$, Mohd Tamizi Mustafa ${ }^{2}$, Mohammed Abdus Salam ${ }^{1}$, Mahmud Sudin ${ }^{3}$, \\ Hashim W. Samsi ${ }^{2}$ \& Mohd Sukhairi Mat Rasat ${ }^{1}$ \\ ${ }^{1}$ Faculty of Earth Science, Universiti Malaysia Kelantan, Jeli 17600, Kelantan, Malaysia \\ ${ }^{2}$ Forest Research Institute Malaysia, Kepong, Kuala Lumpur 52109, Malaysia \\ ${ }^{3}$ School International Tropical Forestry, Universiti Malaysia Sabah, Kota Kinabalu 88999, Sabah, Malaysia \\ Correspondence: Razak Wahab, Faculty of Earth Science, Universiti Malaysia Kelantan, Jeli 17600, Kelantan, \\ Malaysia. Tel: 60-19-8628-787. E-mail: razak@umk.edu.my
}

Received: April 22, 2013 Accepted: June 3, 2013 Online Published: July 15, 2013

doi:10.5539/jas.v5n8p66 URL: http://dx.doi.org/10.5539/jas.v5n8p66

\begin{abstract}
The chemical compositions of cultivated 3 year-old bamboo culms of Gigantochloa brang, G. levis, G. scortechinii and G. wrayi were studied. The culms exhibited different chemical composition in extractives, $\alpha$-cellulose, lignin and ash contents between the bamboo species, location in the culms and position at the nodes and internodes. The extractive content in four species ranged from 8.30 to $9.23 \%$. The extractive content of G.brang, G.levis, G.scortechinii and G.wrayi were $8.30 \%, 9: 23 \%, 8: 00 \%$ and $8.62 \%$ respectively. The holocellulose content for G. levis were $85.08 \%$, G. wrayi $84.53 \%$, G. brang $79.94 \%$ and G. scortechinii $74.62 \%$. The holocellulose content for the cultivated bamboo genus Gigantochloa were $74 \%$ to $85 \%$. The $\alpha$ - cellulose is the chemical constituents in the holocellulose. The highest was G.brang (51.58\%) followed by G. scortechinii (46.87\%), G. wrayi (37.66\%) and G. levis $(33.80 \%)$. The lignin content ranged between 24.84 to $32.65 \%$. The highest were obtained in G. scortechinii (32.55\%), G. wrayi (30.04\%), G. levis $(26.50 \%)$ and lowest in G. brang (24.83\%). The ash content in four species of Gigantochloa bamboo ranged between 0.88 to $2.86 \%$. The ash content is the highest in G. scortechinii (2.83\%) follow by G. levis (1.29\%), G. brang (1.25\%) and the lowest in G. wrayi $(0.88 \%)$.
\end{abstract}

Keywords: bamboo species, holocellulose, hemicellulose, cellulose, lignin, extractives, ash contents

\section{Introduction}

The chemical contents of the bamboo cell walls consisting of cellulose, hemicelluloses and lignin. These materials are composed of large molecules and constitute $90-98 \%$ of the cell wall. The remaining 2 to $10 \%$ composed of lower molecular weight compound called extractives. The main constituents of bamboo culms are holocellulose $(60-70 \%)$, pentosans $(20-25 \%)$, hemicelluloses and lignin (each amounted to about $20-30 \%$ ) and minor constituents like resins, tannins, waxes and inorganic salts (Tomalang et al., 1980). The amount of each component, especially holocellulose, lignin and extractive, varies considerably between the materials. Variation in the chemical constituents occurred in different species, location of cell within the tree (Thomas, 1977; Browing, 1975).

The anatomical, chemical and physical-mechanical properties of bamboo exhibit no basic differences among genera and species compare to wood. Also, growth conditions and aging have apparently no significant effect on composition and structure of the bamboo tissue. In brief, the total culm comprises of about $60 \%$ parenchyma, $40 \%$ fibers and 10\% conducting tissue (vessels and sieve tubes) (Razak et al., 2009; Liese, 1992, 1985)

There exist relationships between the chemical composition and utilization, as bamboo consists of about $50-70 \%$ holocellulose, $30 \%$ pentosans and $20-25 \%$ lignin. There are some differences in these main constituents between species, but any influence on technological properties remains uncertain (Liese, 1992). Cellulose and hemicelluloses are carbohydrate polymers constituents of simple sugars monomers, and lignin is a polymer of phenylpropane units (Browing, 1975). Cellulose is long-chain polymer of glucose which differs from starch in configuration. The fibrous nature of the wood cells is the result of linear, oriented, crystalline arrangement of cellulose component. Hemicelluloses are shorter, or "branched polymers of five-carbon sugars (pentoses), such as 
xylose, or six-carbon sugars (hexoses) other than glucose. They are amorphous in nature and serve with the lignin to form the matrix, in which the cellulose fibrils are embedded. Although the cellulose structure is the same in different species, the hemicelluloses vary considerably among species and especially between hardwoods and soft-woods. Hardwood hemicelluloses are generally richer in pentoses while softwood hemicelluloses generally contain more hexoses.

Lignin, the third cell wall component, is a three-dimensional polymer formed from phenylpropane units which have randomly grown into a complicated large molecule with many different kinds of linkages between the building blocks. Lignin acts as cement between the wood fibres and as a stiffening agent within the fibers. In the production of chemical wood pulps, it is dissolved by various chemical processes, leaving the cellulose and hemicelluloses behind in fibrous form. Some hemicelluloses are lost in the process because of their lower molecular weight, greater solubility and easier hydrolysis.

Chemical composition of cultivated bamboo under genus Gigantochloa (Gigantochloa brang, G. levis, G. scortechinii and G. wrayi) were studied to determine the percentage contents of extractives, $\alpha$-cellulose, lignin and ash contents between them. A comprehensive knowledge of the chemical components in the bamboo species will facilitate the use of the materials in the industrial forestry sector and help to enhance their utilization in the chemical and bio-chemical industrial.

\section{Materials and Method}

\subsection{Raw Material Preparation}

Four (4) species of bamboo namely G. levis, G. scortechinii and G. wrayi were used in this study. The chemical composition of bamboo was determined following the standard outlined in the TAPPI test method T257 (Anon. 1993). Bamboo samples were divided according to species. Every species were divided according to location of the sample which is node and inter node and also, on the basis of position which is outer, middle and inner layer of the bamboo culms. Samples were chipped and dried in an oven at $50^{\circ} \mathrm{C}$ for three (3) days. The dried sample were ground into powder with Willey mill in order to pass BS 40-mesh $(425 \mu \mathrm{m})$ sieve and retained on BS 60-mesh $(250$ $\mu \mathrm{m})$ sieved. The size of the sample must be small to make sure the reaction reagent and fibres are occurring with optimum during the analysis. The chemical composition analysis were used on the bamboo fibre. This method were divided into five stages namely, the material preparation, determination of extractive, holocellulose, cellulose and lignin content.

\subsection{Determination of Organic and Ash}

The major chemical constituents of bamboo from genus Gigantochloa were determined. These include holocellulose, lignin, $\alpha$-cellulose and extractives. The chemical characteristics of bamboo were determined in accordance with the standards outlined in TAPPI test methods. The determination of extractive content were carried out in according to the T204 cm-88 and T264 cm-88 methods (Anon., 1999). The procedure for the ethanol-benzene solubility followed T204 cm-97 (Anon., 2002) for $6 \mathrm{~h}$. Holocellulose were determined following the procedure of Le Wise et al. (1946) and $\alpha$-cellulose base by T203 cm-74 (Anon., 1999). The lignin content were carried out following the T222 cm-88 method (Anon., 2002). The inorganic constituent of lignocellulosic material (referred to its ash content) was considered being the residue remaining after combustion of the organic matter at a temperature of $525 \pm 25^{\circ} \mathrm{C}$. The ash content was determined by followed the procedure outlined in $\mathrm{T} 211 \mathrm{~cm}-93$ method (Anon., 1999).

\section{Results and Discussion}

\subsection{Extractive Content}

Table 1 shows the results of the extractive content for various bamboo species at different location (internodes and nodes) and different position (inner, middle and outer layer of the culm). The extractive content in four species of Gigantochloa bamboo ranged between 8.30 to $9.23 \%$. Norul Hisham et al. (2006) obtained the extractive content of G.scortechinii from 3.4 to 5.8\%. Mahanim et al. (2008) on their study on G.scotechinii and G. lagulata obtained the extractive content ranging from 3.74 to $4.45 \%$ and 2.95 to $3.20 \%$ respectively. The result obtain from this study was higher compared with previous studies. Softwoods constitute $3 \%$ and the hardwoods $5 \%$ extractives (Thomas, 1977). The extractive content of G. brang, G. levis, G. scortechinii and G. wrayi were 8.30\%, 9:23\%, 8:00\% and $8.62 \%$ respectively (Table 1 ). The extractive may constituted roughly from $5 \%$ to $30 \%$ of wood substance in wood, depending on factors such as species, growth conditions, and time of year when the tree were cut.

Results shows that the extractive content in bamboo were less than $10 \%$ and were higher than those found in softwoods and hardwoods. The analysis of Variance (ANOVA) on extractive content (Table 6) showed significant differences on extractive content within the various bamboo culms. The extractive content were noted to be higher 
in G. levis $(9.23 \%)$, followed G. wrayi $(8.62 \%)$, G. brang $(8.30 \%)$ and lowest in G. scortechinii (8\%). At the internodes, the extractive content was $8.46 \%$, while at nodes was $8.63 \%$ for all species. This showed a significant difference between the internodes and nodes in the bamboo culm.

Both the internodes and the nodes have higher extractives content in the inner layers compared to the outer layers of the bamboo. The inner layers of the internodes contains about $12.32 \%$ to $14.17 \%$ and the nodes at 11.90 to 16.41\%, compared with Phyllostachys pubescens at inner layer at 5.78\% (Yoshizawa et al., 1991). Middle position for the internodes was from 5.15 to $9.74 \%$ and for nodes at 5.71 to $7.57 \%$ Compared to $P$. pubescens at middle layer was $4.25 \%$. For the outer layers for internodes was from 3.65 to $4.75 \%$ and for nodes was 4.71 to $6.66 \%$, compared with $P$. pubescens at outer layer was $3.15 \%$. The extractive contain for different layers shows significant differences between the bamboo position for all species (Table 6). The highest extractive content was at $13.42 \%$ inner layer, $7.21 \%$ at the middle layer and $4.99 \%$ at outer layer. A similar trend of extractive content at inner, middle and outer position in bamboo culm was reported by $\mathrm{Li}$ et al. (2007). It showed that the extractive composition between sympodial and monopodial type of bamboo exhibit the similar trend. Li et al. (2007) noted that the inner part has higher extractive content due to wax like materials attached to the inner layer and may have contributed to higher extractive content, compared with the middle and outer layer.

Table 1. Average extractive content various species Genus Gigantochloa

\begin{tabular}{llllll}
\hline Sample Location & Position & G. brang & G. levis & G. scortechinii & G. wrayi \\
\hline \multirow{3}{*}{ Internode } & Outer & $4.42( \pm 0.34)$ & $4.76( \pm 0.38)$ & $3.62( \pm 0.16)$ & $4.54( \pm 0.47)$ \\
& Middle & $5.16( \pm 0.05)$ & $9.89( \pm 0.27)$ & $6.58( \pm 0.28)$ & $9.57( \pm 0.19)$ \\
& Inner & $12.32( \pm 0.24)$ & $14.03( \pm 0.40)$ & $14.17( \pm 0.18)$ & $12.40( \pm 0.48)$ \\
Node & Average & $7.30( \pm 0.21)$ & $9.53( \pm 0.35)$ & $8.16( \pm 0.21)$ & $8.80( \pm 0.38)$ \\
& Outer & $5.25( \pm 0.04)$ & $5.90( \pm 0.80)$ & $4.72( \pm 0.30)$ & $6.66( \pm 1.19)$ \\
& Middle & $6.27( \pm 0.42)$ & $7.53( \pm 0.47)$ & $7.01( \pm 0.15)$ & $5.71( \pm 0.88)$ \\
& Inner & $16.41( \pm 0.25)$ & $13.27( \pm 0.20)$ & $11.91( \pm 0.18)$ & $12.88( \pm 2.61)$ \\
& Average & $9.31( \pm 0.24)$ & $8.93( \pm 0.49)$ & $7.80( \pm 0.21)$ & $8.41( \pm 1.56)$ \\
& Total average & $8.30( \pm 0.23)$ & $9.23( \pm 0.42)$ & $8.00( \pm 0.21)$ & $8.62( \pm 0.97)$ \\
\hline
\end{tabular}

The data presented in this report are average values of at least 5 samples.

\subsection{Holocellulose Content}

The result of the chemical analysis shown in Table 3 indicated only a small difference exist in the holocellulose content between the bamboo species. The highest was G. levis (85.08\%) followed by G. wrayi (84.53\%), G.brang (79.94\%) and G. scortechinii (74.62\%) respectively. Based on this result, the mean average of holocellulose content for the cultivated bamboo genus Gigantochloa were 74\% to 85\%. Tamalong et al. (1980) and Chen et al. (1985) reported that the holocellulose content in bamboo normally consists about $50-70 \%$. The analysis of variance (ANOVA) on holocellulose are tabulated in Table 6 showed that there exist significant different between species. The highest holocellullose contents was $84.53 \%$ found in G. wrayi and $84.52 \%$ in G. levis, G. brang $79.70 \%$ and $G$. scortechinii has the lowest value at $74.62 \%$. An earlier studies by Norul Hisham et al. (2006) found the holocellulose content of $G$. scortechinii was in the range of 78.60 to $82.30 \%$. Ireana (2010) reported that the holocellulose content in B. blumeana was $74.56 \%$. Li et al. (2007) on their study on P. pubescens bamboo showed that the holocellulose content was 63.14 to $69.94 \%$. The value of holocellulose content in bamboo fiber was higher compared to holocellulose content in P. pubescens bamboo and almost similar to softwood fiber (60-80\%) (Tsoumis, 1991; Ashori, 2006).

The holocellulose content in bamboo ranged from $74-85 \%$ and is higher than softwood $(67 \%)$ and also similar and higher then hardwood (75\%). The holocellulose content for G.levis was the higher (85.08\%) followed by G. wrayi (84.53\%), G. brang (79.94\%) and G. scortechinii (74.62\%). The holocellulose content does not show much significant differences at the internodes and nodes of the bamboo culms between the various bamboo species. The content of holocellulose at internodes was $73.48 \%$ to $86.74 \%$ and for the nodes $76.76 \%$ to $85.65 \%$. The holocellulose content were higher at the outer position, and its lower in inner position of the bamboo culms (Table 2). 
Outer layer for the internodes possess about $75.36 \%$ to $91.13 \%$ and for the nodes was 77.80 to $88.55 \%$ of holocellulose, compared with Phyllostachys pubescens at outer layer 69.94\%, middle position for interrnodes were from 71.40 to $84.92 \%$ and the nodes at 77.26 to $88.29 \%$. For the inner layer of internode were 70.69 to $84.17 \%$ and at node was 75.23 to $81.97 \%$. At the inner layer the holocellulose content were $64.54 \%$, the outer layer has $82.99 \%$, middle layer $80.89 \%$ and the inner layer $78.65 \%$.

Similar trend of holocellulose content at inner, middle and outer positon in the monopodial type of bamboo culm was observed by Li et al. (2007). This shows that the holocellulose composition between sympodial and monopodial bamboo exhibit similar trend. The outer layer possess higher holocellulose content due to heavy distribution of vascular bundle compared to the inner layers.

Table 2. Average holocellulose content of Genus Gigantochloa

\begin{tabular}{llllll}
\hline Sample Location & Position & G. brang & G. levis & G. scortechinii & G. wrayi \\
\hline \multirow{3}{*}{ Internode } & Outer & $80.05( \pm 0.93)$ & $89.80( \pm 0.92)$ & $75.35( \pm 0.21)$ & $84.49( \pm 1.45)$ \\
& Middle & $78.29( \pm 0.48)$ & $83.83( \pm 2.55)$ & $71.41( \pm 0.45)$ & $82.75( \pm 0.76)$ \\
& Inner & $76.64( \pm 0.34)$ & $84.08( \pm 0.68)$ & $70.67( \pm 0.27)$ & $82.98( \pm 1.34)$ \\
\multirow{3}{*}{ Node } & Outer & $83.72( \pm 0.55)$ & $84.13( \pm 0.81)$ & $77.84( \pm 0.28)$ & $88.55( \pm 0.77)$ \\
& Middle & $81.97( \pm 1.00)$ & $83.33( \pm 0.21)$ & $77.26( \pm 0.41)$ & $88.28( \pm 1.98)$ \\
& Inner & $77.53( \pm 0.51)$ & $81.97( \pm 0.71)$ & $75.24( \pm 0.29)$ & $80.11( \pm 1.84)$ \\
\hline
\end{tabular}

The data presented in this report are average values of at least 6 samples.

\section{$3.3 \alpha$-cellulose Content}

The analysis of variance (ANOVA) on $\alpha$-cellulose content is showed in Table 6 . Significant difference were noted in the $\alpha$-cellulose content between the various bamboo species. The highest $\alpha$-cellulose content were observed in species G. brang (51.58\%) followed by G. scortechinii (46.87\%), G.wrayi (37.66\%) and G. levis (33.80\%). The $\alpha$-cellulose is one of the chemical constituents in the holocellulose. The $\alpha$-cellulose content for the cultivated bamboo genus Gigantochloa ranged from 33.79 to $51.76 \%$. A similar pattern was obtained by Mahanim et al. (2008) reported that the $\alpha$-cellulose contents in bamboo G.scortechinii and G. lagulata consists about $46.14-46.53 \%$ and $48.4-56.45 \%$ respectively. Other studies on the $\alpha$-cellulose content of $G$. scortechinii was in the range of 63.30 to $64.60 \%$ (Norul Hisham et al., 2006). Ireana (2010) reported that the $\alpha$-cellulose content in bamboo (Bambusa blumeana) consist of $58.72 \%$. Li et al. (2007) on their study on P. pubescens bamboo showed that the $\alpha$ - ellulose content was 41.71 to $49.02 \%$. The value of $\alpha$-cellulose content in bamboo fiber studied was similar compared to $\alpha$ cellulose content in P. pubescens bamboo and almost similar to softwood fiber (42\%) (Thomas, 1977). The $\alpha$-cellulose content in bamboo (33.79-51.76\%) were higher than softwood (42\%) and hardwood (45\%).

The $\alpha$-cellulose content at difference location internode and node in bamboo culm for this genus, did not shows much difference between internodes and nodes. The content of $\alpha$ - cellulose at internode was $31.76 \%$ to $50.82 \%$ and for the node $33.79 \%$ to $51.76 \%$.

Table 3. Average $\alpha$-cellulose content Genus Gigantochloa

\begin{tabular}{llllll}
\hline Sample Location & Position & G. brang & G. levis & G. scortechinii & G. wrayi \\
\hline \multirow{3}{*}{ Internode } & Outer & $56.94( \pm 0.41)$ & $36.96( \pm 0.54)$ & $61.31( \pm 0.43)$ & $44.20( \pm 0.90)$ \\
& Middle & $48.98( \pm 0.27)$ & $32.87( \pm 1.25)$ & $41.59( \pm 0.73)$ & $38.10( \pm 1.42)$ \\
& Inner & $46.34( \pm 0.63)$ & $25.54( \pm 0.52)$ & $39.16( \pm 0.49)$ & $34.62( \pm 1.37)$ \\
Node & Outer & $57.98( \pm 0.79)$ & $46.46( \pm 0.68)$ & $50.02( \pm 0.76)$ & $38.72( \pm 2.39)$ \\
& Middle & $52.71( \pm 1.06)$ & $32.02( \pm 0.20)$ & $46.18( \pm 0.48)$ & $37.80( \pm 2.70)$ \\
& Inner & $46.54( \pm 0.43)$ & $29.00( \pm 0.47)$ & $42.95( \pm 0.23)$ & $32.55( \pm 1.40)$ \\
\hline
\end{tabular}

The data presented in this report are average values of at least 6 samples.

The ANOVA in Table 6 shows no significant difference in $\alpha$-cellulose content between the internodes and nodes. The value of $\alpha$ - cellulose content at internodes was $42.22 \%$ and for the nodes was $42.74 \%$. 
The outer position for the internodes contains $36.99 \%$ to $61.24 \%$ and for the nodes at 38.74 to $58.15 \%$, compared with $P$. pubescens (Moso bamboo) which has $49.02 \%$ at outer layer (Yoshizawa et al., 1991). At the middle position the $\alpha$-cellulose content for internode was from 32.72 to $49.08 \%$ and for node was 32.06 to $53.33 \%$, compared with $P$. pubescens at middle layer was. $45.08 \%$. The inner position, the $\alpha$-cellulose content for internodes was from 25.56 to $46.32 \%$ and for the nodes was 28.95 to $46.61 \%$, compared to $42.84 \%$. in inner layer of $P$. pubescens.

\subsection{Lignin Content}

The Klason lignin or acid insoluble lignin values are shown in Table 4. The results show the lignin content of various bamboo species under genus Gigantochloa at difference location (internode and node) and difference position (inner, middle and outer layer) of the culm. The lignin content in four species of Gigantochloa bamboo is in the ranged of 24.84 to $32.65 \%$. Norul Hisham at el. (2006) Previous obtained lignin content of G.scortechinii at range of 23.40 to $29.00 \%$. Mahanim et al. (2008) on their study on G. scotechinii observed that the lignin content was $16.12-12.48 \%$ and G. lagulata $12.02-11.69 \%$. Ireana (2010) reported that the lignin content in bamboo (B. blumeana) consist of $28.86 \%$. Data obtains from Ireana (2010) study almost comparable with result from this study. Lignin constitute $23 \%$ to $33 \%$ of wood substance in softwood and $16 \%$ to $25 \%$ in hardwoods, Although lignin occurs in wood throughout the cell wall, it is concentrated toward the outside of the cells and between cells.

The analysis of variance (ANOVA) on lignin contents (Table 6) shows significant differences between the bamboo species. The results showed the highest value in G. scortechinii i.e. $32.55 \%$, G. wrayi i.e. $30.04 \%$, G. levis i.e. $26.50 \%$ and lowest value in $G$. brang i.e. $24.83 \%$. The lignin contents in bamboo is almost similar with that of the softwood and hardwood. The lignin content at internodes was $15.72 \%$ to $43.68 \%$, while at nodes was $18.28 \%$ to $33.33 \%$ for all species. The lignin content at the internode was $32.19 \%$ and at the node was $24.76 \%$. There was a significant different between location in bamboo culm. It's clear that internode content higher lignin amount compare to node.

The inner position for the internode contains about $29.88 \%$ to $35.36 \%$ and for the node at 19.66 to $29.93 \%$.In comparison with P. pubescens (Moso bamboo) at inner layer of internodes was $22.57 \%$, the middle layer at 15.70 to $39.40 \%$ and for the nodes was 18.28 to $27.74 \%$, the middle layer was $21.79 \%$ (Yoshizawa et al., 1991). The outer position for the internodes was from 35.98 to $43.68 \%$ and for the nodes was 21.01 to $33.33 \%$, compared with P. pubescens at outer layer was $24.30 \%$. The analysis of variance showed there was a significant difference of lignin content between positions of bamboo culm thickness. The value was highest at outer-layer which was $33.43 \%$, inner layer $30.03 \%$ and the lowest at middle layer which was $21.98 \%$. Similar trend were obtained by Li et al. (2007) on lignin content at inner, middle and outer positon in bamboo culm. There was a clear relationship between the lignin content with the fiber length. The middle position has a long fibre. The outer and inner positions having short fibres possess higher lignin content. Lignin is often called the cementing agent that binds individual cells together (Miller et al., 1999).

\subsection{Ash Content}

Table 5 showed the ash content for various bamboo species under genus Gigantochloa at difference location (internodes and nodes) and difference position which is inner, middle and outer layer of the culm. As it is shown in the table, the mean average of the ash content in four species of Gigantochloa bamboo, which are in the range of 0.88 to $2.86 \%$. Norul Hisham et al. (2006) found that the ash content of G. scortechinii was the ranged of 1.90 to $3.50 \%$. Ireana (2010) reported that the ash content in B. blumeana consist of $1.67 \%$. Both results obtained are comparable with the result obtained from this study.

Table 4. Average lignin content of Genus Gigantochloa

\begin{tabular}{llllll}
\hline Sample Location & Position & G. brang & G. levis & G. scortechinii & G. wrayi \\
\hline \multirow{3}{*}{ Internode } & Outer & $38.75( \pm 0.45)$ & $35.98( \pm 0.42)$ & $43.68( \pm 0.47)$ & $38.90( \pm 0.20)$ \\
& Middle & $15.72( \pm 0.41)$ & $20.34( \pm 0.98)$ & $28.68( \pm 0.40)$ & $22.39( \pm 0.44)$ \\
& Inner & $35.60( \pm 0.66)$ & $33.32( \pm 0.43)$ & $33.57( \pm 0.22)$ & $39.40( \pm 1.12)$ \\
\multirow{3}{*}{ Node } & Outer & $21.01( \pm 0.66)$ & $25.42( \pm 0.84)$ & $33.33( \pm 0.19)$ & $30.34( \pm 2.43)$ \\
& Middle & $18.28( \pm 0.53)$ & $21.67( \pm 0.37)$ & $27.61( \pm 1.04)$ & $21.04( \pm 0.83)$ \\
& Inner & $19.69( \pm 0.62)$ & $22.30( \pm 0.10)$ & $28.42( \pm 1.04)$ & $28.15( \pm 3.80)$ \\
\hline
\end{tabular}

The data presented in this report are average values of at least 6 samples. The data presented in this report are average values of at least 6 samples. 
The highest value for G. scortechinii was $2.83 \%$ follow by G. levis $1.29 \%$, G. brang $1.25 \%$ and the lowest value for G.wrayi $0.88 \%$. Several common wood species have ash contents ranging from $0.43 \%$ (aspen) to $0.87 \%$ (white oak) (Misra et. al. 2004). The bamboo genera Gigantochloa had significantly higher ash content than these common wood species, but similar with kenaf form $1.6-22 \%$ (Ashori, 2006).

The inorganic components of wood are generally expressed as percentage of ash, based on dry weight of the sample. The normal levels of occurrence appear to be from approximately $0.1 \%$ to about $0.5 \%$ ash, for most domestic timbers. Scurlock et al. (2000) reported that Phyllostachys nigra, P. bambusoides, P. bissetii bamboo species from 1 to 4.5 years old have ash content 0.41 to $0.87 \%, 0.53$ to $0.84 \%$, and 0.78 to $1.14 \%$ respectively.

The results in Table 5 showed the ash contents at internodes was $1.00 \%$ to $2.32 \%$, while at nodes was $0.88 \%$ to $2.86 \%$ for all species. There is no significant difference of ash content between the internodes and nodes in the culm.

The ash contents at the inner position for the internode were about $1.38 \%$ to $3.39 \%$ and for the node was 0.53 to 4.79\%, compared with Phyllostachys pubescens (Moso bamboo) at inner layer was $0.88 \%$, At the middle layer position for the interrnode was from 0.86 to $2.03 \%$ and for the node was 0.64 to $2.62 \%$ compared with $P$. pubescens at middle layer was $0.65 \%$. For the outer layer position for the internode was from 0.78 to $1.53 \%$ and for the node was 0.71 to $2.80 \%$, compared with $P$. pubescens at outer layer was $0.54 \%$. Li et al. (2007) from their study showed the similar trend of ash content at inner, middle and outer positon in bamboo culm. It's showed that the ash composition between sympodial and monopodial type of bamboo, has a similar trend.

Table 5. Average Ash content Genus Gigantochloa

\begin{tabular}{llllll}
\hline Sample Location & Position & G. brang & G. levis & G. scortechinii & G. wrayi \\
\hline \multirow{3}{*}{ Internode } & Outer & $0.78( \pm 0.04)$ & $1.19( \pm 0.14)$ & $1.50( \pm 0.11)$ & $0.97( \pm 0.12)$ \\
& Middle & $0.84( \pm 0.06)$ & $1.26( \pm 0.18)$ & $2.04( \pm 0.06)$ & $0.97( \pm 0.13)$ \\
& Inner & $1.38( \pm 0.12)$ & $1.41( \pm 0.11)$ & $3.35( \pm 0.23)$ & $1.41( \pm 0.18)$ \\
\multirow{3}{*}{ Node } & Outer & $1.26( \pm 0.24)$ & $1.66( \pm 0.26)$ & $2.80( \pm 0.14)$ & $0.72( \pm 0.14)$ \\
& Middle & $0.83( \pm 0.06)$ & $1.03( \pm 0.02)$ & $2.63( \pm 0.11)$ & $0.66( \pm 0.12)$ \\
& Inner & $1.13( \pm 0.11)$ & $1.24( \pm 0.15)$ & $4.70( \pm 0.28)$ & $0.53( \pm 0.24)$ \\
\hline
\end{tabular}

The data presented in this report are average values of at least 6 samples.

\subsection{Comparison of Chemical Composition}

Table 6. Summary Result for Analysis of Variance (ANOVA) for chemical composition between species, location and position

\begin{tabular}{|c|c|c|c|c|c|}
\hline & \multicolumn{5}{|c|}{ Chemical Composition } \\
\hline & Extractive & Holocellulose & Alpha Cellulose & Lignin & Ash \\
\hline \multicolumn{6}{|l|}{ SPECIES } \\
\hline G.brang & $8.30 \mathrm{~b}$ & $79.70 \mathrm{~b}$ & $51.58 \mathrm{a}$ & $24.83 \mathrm{c}$ & $1.26 \mathrm{cb}$ \\
\hline G.levis & $9.23 \mathrm{a}$ & $84.52 \mathrm{a}$ & $33.81 \mathrm{~d}$ & $26.50 \mathrm{c}$ & $1.30 \mathrm{~b}$ \\
\hline G.scortechinii & $8.00 \mathrm{~b}$ & $74.63 \mathrm{c}$ & $46.87 b$ & $32.55 \mathrm{a}$ & $2.84 \mathrm{a}$ \\
\hline G.wrayi & $8.62 \mathrm{ab}$ & $84.53 \mathrm{a}$ & $37.66 \mathrm{c}$ & $30.04 b$ & $0.88 \mathrm{c}$ \\
\hline \multicolumn{6}{|l|}{ LOCATION } \\
\hline Internode & $8.46 \mathrm{~b}$ & $80.03 b$ & $42.22 \mathrm{a}$ & $32.19 \mathrm{a}$ & $1.54 \mathrm{~b}$ \\
\hline Node & $8.63 \mathrm{a}$ & $81.66 \mathrm{a}$ & $42.74 \mathrm{a}$ & $24.76 b$ & $1.60 \mathrm{a}$ \\
\hline \multicolumn{6}{|l|}{ POSITION } \\
\hline Outer layer & $4.99 c$ & $82.99 \mathrm{a}$ & $49.07 \mathrm{a}$ & $33.43 a$ & $1.52 \mathrm{~b}$ \\
\hline Middle layer & $7.21 \mathrm{~b}$ & $80.89 b$ & $41.28 b$ & $21.98 \mathrm{c}$ & $1.28 \mathrm{c}$ \\
\hline Inner layer & $13.42 \mathrm{a}$ & $78.65 \mathrm{c}$ & $37.09 \mathrm{c}$ & $30.03 b$ & $1.89 \mathrm{a}$ \\
\hline
\end{tabular}

Means followed by the same letter in a column is not significant different at 0.05 probability level. 


\subsection{Comparison between Chemical Composition with Moisture Content and Specific Gravity}

Moisture contents were proportional to the extractive content. The higher the moisture content, the higher the extractive content. Lignin content does not show significantly correlation with moisture content. The correlation was rather weak and the moisture content has no direct relationship with lignin content in bamboo. Holocellulose and alpha-cellulose content has significant correlation with moisture content. They correlate quite well where the location and position with high moisture content, it related directly with low contents of holocellulose and alpha-cellulose.

The ash content has a positive correlation with moisture content. This means that the location and position that contains a high moisture content, ash directly a rate that is higher. Water contents were most likely contained minerals or inorganic materials. Ash was an indicator of the presence inorganic materials in the lignocellulose material.

Table 7 shows correlation between chemical compositions with specific gravity. Extractive content has a significant correlation with specific gravity of bamboo. This shows the inverse relationship which a higher specific gravity, extractive content was low.

Lignin content has a significant correlation with specific gravity. This means that the location and position has a high specific gravity, the lignin content was relatively high. It shows the role of lignin as cement for cell bonding. This clearly shows a weak correlation between specific gravity and lignin content.

Holocellulose and alpha-cellulose has a significant correlation with specific gravity. This shows a strong and positively relationship, meaning a high specific gravity, which was attributed to the presence of a high holocellulose and alpha-cellulose. The ash content with specific gravity relationship is not consistent and not significant.

Table 7. Correlation coefficients of different chemical composition with bamboo in genus Gigantochloa moisture content and specific gravity

\begin{tabular}{llll}
\hline Properties & Species & MC & SG \\
\hline Extractive & G. brang & $0.69^{*}$ & $-0.77^{*}$ \\
& G. levis & $0.75^{*}$ & $-0.83^{*}$ \\
& G. scortechinii & $0.84^{*}$ & $-0.83^{*}$ \\
Gignin & G. wrayi & $0.50^{*}$ & $-0.73^{*}$ \\
& G. brang & $0.09 \mathrm{~ns}$ & $0.24^{*}$ \\
& G. levis & $0.01 \mathrm{~ns}$ & $0.18^{*}$ \\
& G. scortechinii & $0.09 \mathrm{~ns}$ & $0.38^{*}$ \\
Holocellulose & G. wrayi & $0.09 \mathrm{~ns}$ & $0.22^{*}$ \\
& G. brang & $-0.77^{*}$ & $0.79^{*}$ \\
& G. levis & $-0.34^{*}$ & $0.48^{*}$ \\
Alpha-cellulose & G. scortechinii & $-0.61^{*}$ & $0.49^{*}$ \\
& G. wrayi & $-0.39^{*}$ & $0.56^{*}$ \\
& G. brang & $-0.83^{*}$ & $0.94^{*}$ \\
& G. levis & $-0.71^{*}$ & $0.81^{*}$ \\
& G. scortechinii & $-0.70^{*}$ & $0.78^{*}$ \\
& G. wrayi & $-0.43^{*}$ & $0.74^{*}$ \\
& G. brang & $0.35^{*}$ & $-0.16^{*}$ \\
& G. levis & $0.20^{*}$ & $-0.22^{*}$ \\
& G. scortechinii & $0.38^{*}$ & $-0.24^{*}$ \\
& G. wrayi & $0.25^{*}$ & $-0.08 \mathrm{~ns}$ \\
\hline
\end{tabular}

$\mathrm{MC}=$ moisture content, $\mathrm{SG}=$ specific gravity, $\mathrm{ns}=$ not significant, $*=$ significant at $0.05, *=$ significant at 0.05 probability level. 


\subsection{Comparison between Chemical Composition with Anatomy and Fiber Morphology}

Table 8 shows that the extractive content has a clear relationship with the number of vascular bundle. This means that the number of vascular bundle increases, depleted extractive content. This means that the larger size of the vascular bundle, the higher the extractive content in bamboo.

Lignin content had a significant correlation with the number of vascular bundle. This indicates heavy distribution of the vascular budle. The was a weak correlation between vascular bundle size (length and width) with lignin content.

The correlation between fiber morphology (Table 8) shows no relationship exist between lignin content and the fiber fiber length, but there was a clear correlation on the lignin content and fiber diameter. Lignin content increases when the fiber diameter were smaller, this confirms the presence of lignin as binder to bind the fibers. Small diameter fibers need a lot of binder (lignin) to form a combined cell structure of bamboo.

The lumen diameter has a negative relationship with lignin content. Lignin content had a significant correlation with the wall thickness. This means the fiber has a thin wall thickness has higher lignin content at that area.

Table 7 shows the holocellulose contents and alphacellulose was positively correlate with the number of vascular bundle. Instead, it has a negative relationship with the vascular bundle size (length and width). Holocellulose and alphacellulose content was not showing a clear relationship with the fiber morphology properties. Similarly, ash content of the relationship, it was also not clear.

Table 8. Correlation coefficients of different chemical composition with anatomical and fibre properties of various bamboo species genus Gigantochloa

\begin{tabular}{|c|c|c|c|c|c|c|c|c|}
\hline \multirow[t]{2}{*}{ Properties } & \multirow[t]{2}{*}{ Species } & \multicolumn{3}{|c|}{ Anatomical Properties } & \multicolumn{4}{|c|}{ Fibre Properties } \\
\hline & & $\begin{array}{l}\text { No. } \\
\text { Vascular } \\
\text { Bundle }\end{array}$ & $\begin{array}{l}\text { Vascularbundle } \\
\text { length }\end{array}$ & $\begin{array}{l}\text { Vascularbundle } \\
\text { width }\end{array}$ & $\begin{array}{l}\text { Fibre } \\
\text { length }\end{array}$ & $\begin{array}{l}\text { Fibre } \\
\text { diameter }\end{array}$ & $\begin{array}{l}\text { Lumen } \\
\text { diameter }\end{array}$ & $\begin{array}{l}\text { Wall } \\
\text { thickness }\end{array}$ \\
\hline \multirow[t]{4}{*}{ Extractive } & G. brang & $-0.64^{*}$ & $0.68^{*}$ & $0.48^{*}$ & $0.01^{\mathrm{n}}$ & $0.09^{*}$ & $0.13^{*}$ & $-0.07^{\mathrm{n}}$ \\
\hline & G. levis & $-0.65^{*}$ & $0.77^{*}$ & $0.65^{*}$ & $0.08^{\mathrm{n}}$ & $0.16^{*}$ & $0.09^{*}$ & $-0.15^{*}$ \\
\hline & G. scortechinii & $-0.84^{*}$ & $0.65^{*}$ & $0.49^{*}$ & $0.06^{\mathrm{n}}$ & $0.10^{*}$ & $0.12^{*}$ & $-0.12^{*}$ \\
\hline & G. wrayi & $-0.37^{*}$ & $0.67^{*}$ & $0.32^{*}$ & $0.01^{\mathrm{n}}$ & $0.09^{\mathrm{n}}$ & $0.09^{\mathrm{n}}$ & $-0.14^{*}$ \\
\hline \multirow[t]{4}{*}{ Lignin } & G. brang & $0.35^{*}$ & $0.01^{\mathrm{n}}$ & $-0.42^{*}$ & $-0.05^{\mathrm{n}}$ & $-0.47^{*}$ & $-0.23^{*}$ & $-0.41^{*}$ \\
\hline & G. levis & $0.37^{*}$ & $0.11^{*}$ & $-0.23^{*}$ & $-0.03^{\mathrm{n}}$ & $-0.35^{*}$ & $-0.23^{*}$ & $-0.31^{*}$ \\
\hline & G. scortechinii & $0.72^{*}$ & $0.14^{*}$ & $-0.59^{*}$ & $-0.09^{\mathrm{n}}$ & $-0.30^{*}$ & $-0.37^{*}$ & $-0.38^{*}$ \\
\hline & G. wrayi & $0.38^{*}$ & $0.21^{*}$ & $-0.32^{*}$ & $-0.07^{\mathrm{n}}$ & $-0.36^{*}$ & $-0.22^{*}$ & $-0.37^{*}$ \\
\hline \multirow{4}{*}{$\begin{array}{l}\text { Holo- } \\
\text { cellulose }\end{array}$} & G. brang & $0.30^{*}$ & $-0.44^{*}$ & $-0.13^{*}$ & $-0.00^{\mathrm{n}}$ & $-0.35^{*}$ & $-0.04^{\mathrm{n}}$ & $0.23^{*}$ \\
\hline & G. levis & $0.54^{*}$ & $-0.33^{*}$ & $-0.12^{*}$ & $-0.03^{\mathrm{n}}$ & $-0.34^{*}$ & $-0.18^{*}$ & $0.29^{*}$ \\
\hline & G. scortechinii & $0.40^{*}$ & $-0.13^{*}$ & $-0.06^{*}$ & $-0.02^{\mathrm{n}}$ & $-0.35^{*}$ & $-0.13^{*}$ & $0.36^{*}$ \\
\hline & G. wrayi & $0.31^{*}$ & $-0.43^{*}$ & $-0.16^{*}$ & $-0.05^{\mathrm{n}}$ & $-0.34^{*}$ & $-0.07^{\mathrm{n}}$ & $0.10^{*}$ \\
\hline \multirow{4}{*}{$\begin{array}{l}\text { Alpha- } \\
\text { cellulose }\end{array}$} & G. brang & $0.65^{*}$ & $-0.66^{*}$ & $-0.40^{*}$ & $-0.30^{*}$ & $-0.08^{n}$ & $-0.21^{*}$ & $-0.02^{\mathrm{n}}$ \\
\hline & G. levis & $0.57^{*}$ & $-0.75^{*}$ & $-0.76^{*}$ & $-0.28^{*}$ & $-0.14^{*}$ & $-0.03^{\mathrm{n}}$ & $-0.14^{*}$ \\
\hline & G. scortechinii & $0.86^{*}$ & $-0.60^{*}$ & $-0.47^{*}$ & $-0.28^{*}$ & $-0.04^{\mathrm{n}}$ & $-0.24^{*}$ & $-0.15^{*}$ \\
\hline & G. wrayi & $0.55^{*}$ & $-0.75^{*}$ & $-0.53^{*}$ & $-0.27^{*}$ & $-0.00^{\mathrm{n}}$ & $-0.14^{*}$ & $-0.05^{\mathrm{n}}$ \\
\hline \multirow[t]{4}{*}{ Ash } & G. brang & $-0.23^{*}$ & $0.27^{*}$ & $-0.03^{\mathrm{n}}$ & $-0.18^{*}$ & $-0.08^{n}$ & $-0.08^{\mathrm{n}}$ & $-0.14^{*}$ \\
\hline & G. levis & $-0.12^{*}$ & $-0.05^{\mathrm{n}}$ & $-0.07^{\mathrm{n}}$ & $-0.02^{\mathrm{n}}$ & $-0.11^{*}$ & $-0.03^{\mathrm{n}}$ & $-0.10^{*}$ \\
\hline & G. scortechinii & $-0.22^{*}$ & $0.26^{*}$ & $-0.13^{*}$ & $-0.06^{\mathrm{n}}$ & $-0.13^{*}$ & $-0.14^{*}$ & $-0.25^{*}$ \\
\hline & G. wrayi & $-0.26^{*}$ & $-0.27^{*}$ & $-0.23^{*}$ & $-0.12^{*}$ & $-0.17^{*}$ & $-0.10^{*}$ & $-0.16^{*}$ \\
\hline
\end{tabular}




\section{Conclusions}

The extractive content in four species of Gigantochloa bamboo is in the range of 8.30 to $9.23 \%$. The extractive content of G.brang, G. levis, G. scortechinii and G. wrayi are $8.30 \%, 9: 23 \%, 8: 00 \%$ and $8.62 \%$ respectively. The extractive content was higher in G. levis $(9.23 \%)$, followed G. wrayi $(8.62 \%)$, G. brang $(8.30 \%)$ and lowest value in G. scortechinii (8\%). The extractive content at internode was $8.46 \%$, while at the node was $8.63 \%$ for all species. Inner position for the internodes the extractives contains were $12.32 \%$ to $14.17 \%$ and for the node were 11.90 to $16.41 \%$. The middle position for internode were from 5.15 to $9.74 \%$ and node were 5.71 to $7.57 \%$. The extractive content was at $13.42 \%$ (inner layer), $7.21 \%$ (middle layer) and $4.99 \%$ (outer layer).

The holocellulose content for G. levis was $85.08 \%$, G. wrayi $84.53 \%$, G. brang $79.94 \%$ and G. scortechinii $74.62 \%$. The holocellulose content for the cultivated bamboo genus Gigantochloa were $74 \%$ to $85 \%$. The content of holocellulose at internode was $73.48 \%$ to $86.74 \%$ and for the node $76.76 \%$ to $85.65 \%$. The holocellulose content is highest at internode (81.65\%) compared to node $(80.02 \%)$.

The highest was G. brang (51.58\%) followed by G. scortechinii $(46.87 \%)$, G. wrayi $(37.66 \%)$ and G. levis (33.80\%). Based from the result, the average of $\alpha$-cellulose content for the cultivated bamboo genus Gigantochloa were 33.79 to $51.76 \%$. The $\alpha$-cellulose content at difference location internode and node in bamboo culm for this genus, showing not much differences between internodes and nodes. The content of $\alpha$-cellulose at internodes was $31.76 \%$ to $50.82 \%$ and for the nodes $33.79 \%$ to $51.76 \%$. The average value of $\alpha$ - cellulose content at internodes was. $42.22 \%$ and for the nodes was $42.74 \%$.

The lignin content in the four species of Gigantochloa bamboo ranged between 24.84 to $32.65 \%$. The highest were obtained in G. scortechinii (32.55\%), G. wrayi (30.04\%), G. levis (26.50\%) and lowest in G. brang (24.83\%). The lignin content at the internodes were $15.72 \%$ to $43.68 \%$, while at nodes were $18.28 \%$ to $33.33 \%$ for all species.

The ash content in four species of Gigantochloa bamboo ranged between 0.88 to $2.86 \%$. The ash content is the highest in G. scortechinii (2.83\%) follow by G. levis (1.29\%), G. brang $(1.25 \%)$ and the lowest in G.wrayi $(0.88 \%)$. The ash content at internodes ranged from $1.00 \%$ to $2.32 \%$, while at nodes was $0.88 \%$ to $2.86 \%$ for all species. The ash content were higher at nodes compared to internodes. The ash contents at the inner position for the internodes ranged between $1.38 \%$ to $3.39 \%$ and the nodes was 0.53 to 4.79 .ListenRead phonetically

\section{References}

Anonymous. (1993). Technical Association of the Pulp and Paper Industry: Sampling and preparing wood for analysis (Test Method T $257 \mathrm{~cm}$-12). Atlanta, USA.

Anonymous. (1999). Technical Association of the Pulp and Paper Industry: Sampling and preparing wood for analysis Technical Association of the Pulp and Paper Industry. TAPPI Standard T203 cm-99. Atlanta, USA.

Anonymous. (2002). Technical Association of the Pulp and Paper Industry: Sampling and preparing wood for analysis Technical Association of the Pulp and Paper Industry. TAPPI Standard T222 om-02. Atlanta, USA.

Ashori, A. (2006). Pulp and paper from Kenaf bast fibers. Journal of Fibers and Polymers, 7(1), 26-29. http://dx.doi.org/10.1007/BF02933598

Browning, B. L. (1975). The chemistry of wood. Robert E. Krieger Publishing Company.

Ireana, Y. (2010). Cell Wall Architecture, Properties and Characteristics of Bamboo, Kenaf and Rice Straw Fibers. M.Sc Thesis, USM.

Le Wise, M., Murphy, A. A., d'Addieco-Paper, Tr. J. (1946). Chlorite Holocellulose, its Fractionnation and Bearing on Summative Wood Analysis and on Studies on the Hemicelluloses.

Li, X. B., Shape, T. F., Peter, G. F., Hse, C. Y., \& Eberhardt, T. L. (2007). Chemical changes with maturation of the bamboo species Phyllostachys pubescens. Journal of Tropical Forest Science, 19(1), 6-12.

Liese, W. (1985). Anatomy and properties of bamboo. Recent research on bamboos. Proceedings of the International Bamboo Workshop. October 6-14, 1985, Hangzhou, China.

Liese, W. (1992). The structure of bamboo in relation to its properties and utilization. In S. Zhu, W. Li, X. Zhang, \& Z. Wang (Eds.), Bamboo and its use (pp. 96-100). Proceedings of the International symposium on Industrial Use of Bamboo, Beijing, China, 7-11 December 1992. International Tropical Timber Organization: Chinese Academy of Forestry, Beijing, China.

Mahanim, S. M. A., Puad, E., Rafidah, J., Wan Asma, I., \& Shaharuddin, H. (2008). A Study on Physical and Chemical Properties of Gigantochloa scortechinii and Gigantochloa ligulata. Utilisation of Oil Palm Tree: Strategizing for Commercial Exploitation. Forest Products Journal, Forest Research Institut Malaysia. 
Norul Hisham, H., Othman, S., Rokiah, H., Abd. Latif, M., Ani, S., \& Mohd. Tamizi, M. (2006). Characterization of Bamboo Gigantochloa scortechinii different ages. Journal of Tropical Forest Science, 18(4), 236-242, Forest Research Institute Malaysia, 52109 Kepong, Selangor Darul Ehsan, Malaysia

Razak, W., Mohammed, A., Mustafa, M. T., \& Hassan, A. (2009). Physical characteristics and anatomical properties of cultivated bamboo (Bambus vulgaris schrad) culms. Journal of Biological Sciences, 9(7), 753-759. http://dx.doi.org/10.3923/jbs.2009.753.759

Scurlock, J. M. O., Dayton, D. C., \& Hames, B. (2000). Bamboo: An overlooked biomass resource? Biomass and Bioenergy, 19(2000), 229-244. http://dx.doi.org/10.1016/S0961-9534(00)00038-6

Thomas, R. J. (1977). Wood: Structure and Chemical Composition in Wood Technology Chemical Aspects. American Chemical Society (ACS) Symposium (Series 43, p. 21).

Tomalang, F. N., Lopez, A. R., Semara, J. A., Casin, R. F., \& Espiloy, Z. B. (1980). Properties and utilization of Philippine erect bamboo. In Lessard, G., \& Chouinard, A. (Eds), International Seminar on Bamboo Research in Asia held in Singapore, May 28-30, 1980: proceedings (pp. 266-275). Singapore: International Development 44 Research Center and the International Union of Forestry Research Organization.

Yoshizawa, N., Satoh, T., Yokota, S., \& Idei, T. (1991). Lignification and peroxidase activity in bamboo shoots (Phyllostachys edulis), 45(3), 169-174.

\section{Copyrights}

Copyright for this article is retained by the author(s), with first publication rights granted to the journal.

This is an open-access article distributed under the terms and conditions of the Creative Commons Attribution license (http://creativecommons.org/licenses/by/3.0/). 